\title{
Comparison of two low dose local anesthetics in combination with morphine for spinal anesthesia for total knee arthroplasty
}

\author{
Handan Gulec ${ }^{1}$, Esra Ozayar², Asli Alkan³ ${ }^{3}$ Merve Kacan ${ }^{4}$, Munire Babayigit ${ }^{2}$, Aysun Kurtay², \\ Ismail Demirkale ${ }^{2}$, Eyup Horasanli ${ }^{1}$ \\ 1-Ankara Yildirim Beyazit University, Kızılca Mahallesi, 06760 Çubuk, Ankara, Turkey. \\ 2- Ankara Keçiören Training And Research Hospital, Kecioren, Ankara, Turkey. \\ 3- Muğla Sıtkı Koçman University Training and Research Hospital, Mugla, Turkey. \\ 4- Beylikdüzü Kolan Hospital, Adnan Kahveci, Osmanlı Cd. No:23, 34528 Beylikdüzü/İstanbul, Turkey.
}

Correspondence: Handan Güleç; E-mail: handandrhandan@yahoo.com.tr; Mobile: +90 5056725948

\section{Abstract}

Background: There is a lack of consensus on the combination doses of local anesthetics and opioids for spinal anesthesia in patients undergoing total knee arthroplasty (TKA) surgery. Opioids and local anesthetic combinations are associated with many postoperative side effects at high doses. We aimed to assess the use of the lowest possible doses of intrathecal bupivacaine and morphine for TKA.

Methodology: Sixty-six patients undergoing TKA were randomly divided into two groups. In both groups, combined spinal epidural anesthesia was administered. Group 1 received $5 \mathrm{mg}$ of heavy bupivacaine and $0.1 \mathrm{mg}$ of morphine, and Group 2 received $7.5 \mathrm{mg}$ of heavy bupivacaine and $0.1 \mathrm{mg}$ of morphine. Ketamine and propofol were used for sedation. Intraoperative vital signs (blood pressure, heart rate, and pulse oxygen saturation), duration of the surgery, onset duration of spinal anesthesia, and side effects, including nausea, vomiting, itching, and respiratory distress were recorded. Patient satisfaction was assessed postoperatively using the visual analogue scale (VAS). Surgeon's satisfaction was also assessed. Epidural patientcontrolled analgesia (PCA) with bupivacaine was used for postoperative pain management, and diclofenac sodium was used as a rescue analgesic.

Results: There was no statistically significant difference in the duration of onset of spinal anesthesia, but the duration of the onset spinal anesthesia was longer in Group 2. There was no statistically significant difference in surgeon satisfaction or between-group difference in patient satisfaction. The VAS score 4 and $24 \mathrm{~h}$ after the surgery were significantly low in Group 1. Rescue analgesic consumption in Group 1 was significantly higher than in Group 2.

Conclusion: A combination of low-dose opioids and local anesthetic in spinal anesthesia may be an alternative to high doses, with fewer postoperative side effects.

Citation: Gulec H, Ozayar E, Alkan A, Kacan M, Babayigit M, Kurtay A, et al. Comparison of two low dose local anesthetics in combination with morphine for spinal anesthesia for total knee arthroplasty. Anaesth. pain \& intensive care 2020;24(4):397402.

Received: 13 December 2019, Reviewed: 23 March 2020, Revised: 17 May 2020, Accepted: 25 June 2020

\section{Introduction}

Owing to the extreme tissue dissection involved, TKA is often cited as one of the most painful known procedures. ${ }^{1}$ Approximately, $20 \%$ of patients with osteoarthritis of the knee do not want to undergo TKA because of the expectancy of high levels of pain. ${ }^{2}$ Management of postoperative pain is an important part 
of peri-operative care of the patients undergoing total knee arthroplasty (TKA). After knee surgery, the pain may also inhibit early rehabilitation to mobilize the knee joint. ${ }^{1}$ The treatment of postoperative pain is crucial for homeostasis. Additionally, it has a significant impact not only on lowering the cost of treatment but also on the patient's recovery time and consequently on the total hospital stay. ${ }^{3}$ Tissue trauma during major surgery often leads to changes in pain perception by the central nervous system. ${ }^{4}$ This can cause muscle atrophy and capsular contractures that may impair the functional outcome. There are many analgesic options available for TKA that vary in terms of complexity, efficacy, side effects and potential complications. ${ }^{5}$ Ineffective pain control after TKA can cause many side effects. ${ }^{6}$ There is no consensus on postoperative pain control after TKA, with many trials aimed to find the best combination of opioids and local anesthetic agents. Intrathecal morphine (ITM) combined with bupivacaine spinal anesthesia can improve postoperative pain, but has potential side effects of postoperative nausea/vomiting (PONV) and pruritus. With the use of multimodal analgesia and regional anesthetic techniques, postoperative pain control has improved significantly to a point where ITM may be avoided in total joint arthroplasty. ${ }^{7}$

Different types of local anesthesia applications can successfully treat TKA pain. Although opioids and continuous epidural analgesia remain the major options for the postoperative pain management of TKA, they have some undesirable side effects. Many postoperative pain control approaches, including neuraxial techniques, continuous nerve blocks, and IV patient-controlled analgesia (PCA), are available for TKA. Although morphine is the most well-known and preferred intrathecal agent due to its prolonged analgesic effect, there is no consensus in the literature on the optimum dosage because of concerns about side effects.

The aim of this prospective, randomized, double-blind study was to compare two different doses of bupivacaine, in addition to morphine, on side effects and patient's and surgeon's satisfaction.

\section{Methodology}

After obtaining the approval of the ethics committee of Kecioren Training and Research Hospital and written informed consent, 66 patients with ASA physical status I-III undergoing unilateral TKA were enrolled in the study. Patients who were allergic to the medications in the study or had a contraindication to spinal anesthesia $(\mathrm{Hb}<8 \mathrm{~g} / \mathrm{dl})$ were excluded from the study.

The patients were randomly allocated to two groups using the sealed envelope method. Preoperatively, all the patients received $1000 \mathrm{ml}$ of Ringer's lactate solution in $30 \mathrm{~min}$. Midazolam $(0.01 \mathrm{mg} / \mathrm{kg})$ was administered as premedication, and the patients were monitored. Using the L4-5 interspace, a combined spinal epidural blockage was performed, with the patient in a sitting position.

The patients in Group 1 were administered $5 \mathrm{mg}$ of bupivacaine and $0.1 \mathrm{mg}$ of morphine. The patients in Group 2 received $7.5 \mathrm{mg}$ of bupivacaine and $0.1 \mathrm{mg}$ of morphine.

In both groups, the drugs were administered via the intrathecal route into the subarachnoid space. The total volume in each syringe was $2 \mathrm{ml}$ in both groups. The syringes were prepared and labeled by a third-year resident and delivered to the study team. After subarachnoid blockage, an epidural catheter was inserted. A combination of $1 \mathrm{mg} / \mathrm{kg}$ ketamine and propofol was given prior to the incision to reduce intraoperative anxiety. The sedation level of the patient was assessed using the Ramsay sedation scale and complains of pain.

Intravenously (IV) administered ephedrine (10 mg) was planned to be given to patients whose systolic blood pressure fell below $90 \mathrm{mmHg}$ or decreased by more than $20 \%$ of baseline. Metoclopramide (10 mg) was used as a rescue case of itching. For the epidural postoperative pain management, an epidural catheter was set to $5 \mathrm{ml} / \mathrm{hr}$ bupivacaine infusion without loading and bolus dose that $(20 \mathrm{ml}$ bupivacaine was added to $80 \mathrm{ml}$ serum. In total, $20 \mathrm{ml}$ bupivacaine to $100 \mathrm{ml}$ fluid $=0.2$ ). We applied hourly infusion because our patients were old. Locked time of controlled analgesia also set $20 \mathrm{~min}$. Our patientcontrolled analgesic dose proved to be sufficient.

Demographic data on the patients, including their age, gender, weight, and height, were recorded on a study sheet. Systolic, diastolic, and mean blood pressure, in addition to heart rate and pulse oxygen saturation, after $1,10,20,30,40,60$, and $120 \mathrm{~min}$ were recorded 
intraoperatively, as well as additional drug usage and dosages. The duration of the surgery was also recorded. The motor blockage was assessed using the Bromage scale. The time of recovery from motor blockage was recorded. Patient satisfaction and the quality of recovery were also assessed. Side effects, including, nausea, vomiting, itching, and respiratory distress, were recorded. To assess postoperative pain, the visual analogue scale (VAS) was administered postoperatively 5 and 15 min postsurgery and 2, 6, 12, and $24 \mathrm{~h}$ postsurgery. Patients with appropriate renal functions were selected and diclofenac sodium $(75 \mathrm{mg}$, intramuscular) was used as a rescue analgesic, in addition to epidural PCA. The consumption of rescue analgesics was recorded.

Surgeon's satisfaction was assessed by asking the surgeon postoperatively to score the operation in terms of intraoperative anesthesia, postoperative analgesia, and early mobilization as fair, good, or excellent. Patient satisfaction was assessed by asking the patient to score the anesthesia and postoperative analgesia experience as poor, fair, good or excellent.

\section{Results}

The demographics of the two groups were similar (Table 1). There was no statistically significant difference in the duration of onset of spinal anesthesia, but the duration of spinal anesthesia was longer in Group $2(p<0.001)$.

Table 1: Demographic data and surgical and anesthetic durations

\begin{tabular}{|c|c|c|c|}
\hline Variables & $\begin{array}{l}\text { Group } 1 \\
(n=33)\end{array}$ & $\begin{array}{l}\text { Group } 2 \\
(n=33)\end{array}$ & $\mathbf{p}$ \\
\hline Age $(y)$ & $65.0 \pm 8.8$ & $65.8 \pm 7.0$ & $0.690^{*}$ \\
\hline ASA I/II/III & 2/15/16 & $6 / 17 / 10$ & $0.066^{* *}$ \\
\hline $\begin{array}{l}\text { Body mass index } \\
\left(\mathrm{Kg} / \mathrm{m}^{2}\right)\end{array}$ & $33.6 \pm 6.1$ & $33.0 \pm 5.3$ & $0.686^{*}$ \\
\hline $\begin{array}{l}\text { Time to onset of } \\
\text { spinal anesthesia } \\
\text { (min) }\end{array}$ & $10.4 \pm 2.0$ & $10.3 \pm 2.0$ & $0.738^{*}$ \\
\hline $\begin{array}{l}\text { Duration of } \\
\text { spinal anesthesia } \\
\text { (min) }\end{array}$ & $131.3 \pm 42.4$ & $\begin{array}{l}206.0 \pm \\
102.9\end{array}$ & $\begin{array}{l}< \\
0.001^{*}\end{array}$ \\
\hline $\begin{array}{l}\text { Duration of } \\
\text { surgery (min) }\end{array}$ & $100.9 \pm 20.4$ & $88.7 \pm 19.0$ & $0.015^{*}$ \\
\hline
\end{tabular}

There was no statistically significant difference in surgeon satisfaction between the groups, as shown in Table 2.

Table 2: Surgeon's satisfaction score

\begin{tabular}{l|c|c|c|c|c|c|c}
\multirow{2}{*}{$\begin{array}{l}\text { Surgeon's } \\
\text { satisfaction }\end{array}$} & \multicolumn{2}{|c|}{ Group 1 } & \multicolumn{2}{|c|}{ Group 2 } & \multicolumn{2}{|c|}{ Total } & \multirow{2}{*}{$\mathbf{n}$} \\
\cline { 2 - 7 } & $\mathbf{n}$ & $\%$ & $\mathbf{n}$ & $\%$ & $\mathbf{n}$ & $\%$ & \\
\hline Fair & 1 & 3.0 & 0 & 0.0 & 1 & 1.5 \\
\hline Good & 9 & 27.3 & 5 & 15.2 & 14 & 21.2 & 0.268 \\
\hline Excellent & 23 & 69.7 & 28 & 84.8 & 51 & 77.3 & \\
\hline Total & 33 & 100.0 & 33 & 100.0 & 66 & 100.0
\end{tabular}

${ }^{*}$ Chi-square test

There was no difference in patient satisfaction between the groups $(p=0.180)$. The comparative values are given in Table 3. Almost $90 \%$ patients had had good to excellent satisfaction scores. But the difference in between the two groups was not significant.

The VAS values $4 \mathrm{~h}$ and $24 \mathrm{~h}$ postsurgery were significantly low in Group 1 (Table 4); however, at other times the VAS scores were statistically equivalent.

Rescue analgesic consumption in Group 1 was significantly higher than in Group 2, e.g., [21 (63\%) vs. $6(18 \%)(p<0.001)]$.

The frequency of pruritus and vomiting was higher in Group 1 patients as compared to Group 2. The frequency of postoperative headache was, however, more in Group 2.

\section{Discussion}

Intrathecal opioids added to local anesthetics during spinal anesthesia have been applied in a variety of surgical settings since 1979. Providing prolonged postoperative analgesia without the need for catheters or expensive pumps. However, the use of intrathecal morphine may be associated with distressing side effects, such as itching, urinary retention, nausea and vomiting (PONV), and respiratory depression. ${ }^{8}$

In an attempt to limit opioid side effects, the use of low-dose spinal opioids has been advocated. ${ }^{9}$ Even mini-dose morphine (< $0.1 \mathrm{mg})$ was frequently reported to be effective for managing acute 
Table 3. Patient satisfaction score

\begin{tabular}{l|c|c|c|c|c|c|c}
\multirow{2}{*}{$\begin{array}{l}\text { Patient } \\
\text { satisfaction }\end{array}$} & \multicolumn{2}{|c|}{ Group 1 } & \multicolumn{2}{|c|}{ Group 2 } & \multicolumn{2}{c|}{ Total } & \multirow{2}{*}{ p } \\
\cline { 2 - 7 } & $\mathbf{n}$ & $\%$ & $\mathbf{n}$ & $\%$ & $\mathbf{n}$ & $\%$ & \\
\hline Poor & 0 & 0.0 & 1 & 3.0 & 1 & 1.5 \\
\hline Fair & 6 & 18.2 & 1 & 3.0 & 7 & 10.6 & \\
\hline Good & 8 & 24.2 & 10 & 30.3 & 18 & 27.3 & 0.180 \\
\hline Excellent & 19 & 57.6 & 21 & 63.6 & 40 & 60.6 \\
\hline Total & 33 & 100.0 & 33 & 100.0 & 66 & 100.0 & \\
\hline
\end{tabular}

${ }^{*}$ Chi-square test when compared with those in the present study where $0.1 \mathrm{mg}$ of intrathecal morphine, combined with different doses of heavy bupivacaine, was administered. Among 33 patients of this study reported nausea $(n=$ $12)$, vomiting $(n=8)$, pruritus $(n=13)$, and respiratory depression $(n=1)$ in the $0.2 \mathrm{mg}$ morphine group. In the present study, in Group $1(n=33)$, there were 8 cases of nausea, 7 of vomiting, and 8 of pruritus.

Mohammed A. Alsaeid and his friends studied with the doses which we used. That

Table 4. Comparison of the VAS values of the groups

\begin{tabular}{|c|c|c|c|c|c|c|c|c|}
\hline Time & $5 \mathrm{~min}$ & $15 \mathrm{~min}$ & $30 \mathrm{~min}$ & $2 \mathrm{~h}$ & $4 \mathrm{~h}$ & $6 \mathrm{~h}$ & $12 \mathrm{~h}$ & $24 \mathrm{~h}$ \\
\hline Group 1 & $1.55 \pm 2$ & $1.52 \pm 2.2$ & $1.61 \pm 1.5$ & $1.06 \pm 1.9$ & $0.88 \pm 1.7$ & $1.12 \pm 2.1$ & $1.09 \pm 1.7$ & $0.94 \pm 1.6$ \\
\hline Group 2 & $0.76 \pm 1$ & $0.91 \pm 1.6$ & $1.06 \pm 1.6$ & $1.12 \pm 1.0$ & $1.45 \pm 1.3$ & $1.24 \pm 1.5$ & $0.94 \pm 1.3$ & $1.52 \pm 1.4$ \\
\hline$p$ & 0.240 & 0.239 & 0.101 & 0.131 & $0.015^{*}$ & 0.153 & 0.932 & $0.023^{*}$ \\
\hline
\end{tabular}

Table 5: Number of patients with side effects in both groups

\begin{tabular}{l|l|l} 
Side effects & $\begin{array}{c}\text { Group 1 } \\
\text { (n 33) }\end{array}$ & $\begin{array}{l}\text { Group 2 } \\
\text { (n 33) }\end{array}$ \\
\hline Pruritus & 8 & 4 \\
\hline Headache & 2 & 7 \\
\hline Vomiting & 7 & 3 \\
\hline Nausea & 8 & 7 \\
\hline
\end{tabular}

postoperative pain after variety of surgeries without any evidence of respiratory depression. ${ }^{10,11}$

Achieving high quality pain relief after TKA is possible using regional anesthesia and multimodal pain management. The morphine and bupivacaine doses (250 mcg and $15 \mathrm{mg}$, respectively) applied in their study were higher than those in the present study, and they used IV morphine PCA as a supplementary analgesic. The current study used epidural bupivacaine PCA for postoperative pain management and diclofenac sodium as a rescue analgesic.

Bowrey et al. compared 0.2 and $0.5 \mathrm{mg}$ of intrathecal morphine for postoperative analgesia after total knee replacement and concluded that the higher dose of intrathecal morphine provided better analgesia than the lower dose, without any increase in side effects. ${ }^{12}$ Although the incidence of side effects was similar in the two groups in their study, the rates were higher is why we preferred the same doses. ${ }^{13}$ We used very low dose heavy-bupivacaine in our study but morphine dose $0.1 \mathrm{mg}$ as other studies have applied. The VAS values after 4 and $24 \mathrm{~h}$ were low in Group 1. This may be due to the high consumption of rescue analgesic in this group. There was no statistically significant difference in the duration of onset of spinal anesthesia, but the duration of spinal anesthesia was longer in Group 2 because heavy-bupivacaine dose was higher. Side effects were similar between the two groups. There were no cases of respiratory depression in the present study.

Among the published literature, the number of studies that have used low-dose bupivacaine and morphine in orthopedic surgery is rare. Some studies reported that low-dose spinal opioids limited opioid-related side effects..$^{14,15,16}$ Cole et al. investigated the efficacy and respiratory effects of low-dose spinal morphine for postoperative analgesia after knee arthroplasty. In their study, the patients received $0.3 \mathrm{mg}$ of morphine or saline and $2-2.5 \mathrm{ml}$ of $0.5 \%$ heavy spinal bupivacaine. ${ }^{17}$ Although the VAS scores of the morphine group were improved as compared to those of the control group, they observed a statistically significant reduction in oxygen saturation in the morphine group. The bupivacaine and morphine doses administered in the current study were lower than 
those applied in the study by Cole et al., ${ }^{11}$ and oxygen desaturation did not occur in either group. In addition, $69 \%$ of the surgeons in Group 1 and $84 \%$ of the surgeons in Group 2 assessed their satisfaction as excellent. Among the patients, $57 \%$ and $63 \%$ of those in Group 1 and 2, respectively, rated their satisfaction as excellent. Although the number of patients who rated their satisfaction as excellent was relatively higher in Group 2, the difference was not statistically significant.

Although there was no difference in patient and surgeon's satisfaction, Group 1 required significantly more rescue analgesic, and their VAS values were higher than those of Group 2 after 4 and $24 \mathrm{~h}$. This finding may be explained by the higher use of rescue analgesics in Group 1. Also, in our study, duration of surgery was statistically prolonged in Group 1 which may be the reason of higher consumption of postoperative rescue analgesic. The duration of spinal anesthesia was statistically longer in Group 2. This may be due to higher dose of bupivacaine.

\section{Conclusion}

In conclusion, our results revealed comparatively longer duration of analgesia with $7.5 \mathrm{mg}$ bupivacaine. The side effects were fewer with the use of $5 \mathrm{mg}$ bupivacaine, but patient and surgeon's satisfaction remained good to excellent in both groups. Hence bupivacaine $5 \mathrm{mg}$ combined with $0.1 \mathrm{mg}$ morphine can be used with satisfaction for total knee arthroplasty.

\section{Conflict of interest}

None declared by the authors

\section{Authors' contribution}

HG- Planned the study

ED, AA- Data collection

MK, AK - Spinal block administrator

MB - Statistical analysis of the data

ID - Postoperative care

$\mathrm{EH}$ - Drafted the manuscript

\section{References}

1. Bowrey S, Hamer J, Bowler I, Symonds C, Hall JE. A comparison of 0.2 and $0.5 \mathrm{mg}$ intrathecal morphine for postoperative analgesia after total knee replacement. Anaesthesia. 2005;60(5):449-452. [PubMed] DOI: 10.1111/j.1365-2044.2005.04174.x

2. Jacobson L, Chabal C, Brody MC. A dose-response study of intrathecal morphine: efficacy, duration, optimal dose, and side effects. Anesth Analg. 1988;67(11):1082-1088. [PubMed]

3. Gurbet A, Bekar A, Bilgin H, Korfali G, Yilmazlar S, Tercan M. Pre-emptive infiltration of levobupivacaine is superior to at-closure administration in lumbar laminectomy patients. Eur Spine J. 2008;17(9):12371241. [PubMed] DOI: $10.1007 / s 00586-008-0676-z$

4. Etches RC, Sandler AN, Daley MD. Respiratory depression and spinal opioids. Can J Anaesth. 1989;36(2):165-185. [PubMed] DOl: $\underline{10.1007 / B F 03011441}$

5. Essving P, Axelsson K, Kjellberg J, Wallgren O, Gupta A, Lundin A. Reduced morphine consumption and pain intensity with local infiltration analgesia (LIA) following total knee arthroplasty. Acta Orthop 2010;81:354-360. [PubMed] DOI: 10.3109/17453674.2010.487241

6. Dong J, Li W, Wang Y. The effect of pregabalin on acute postoperative pain in patients undergoing total knee arthroplasty: a meta-analysis. Int J Surg. 2016;34:148160. [PubMed] DOI: $10.1016 /$ i.jisu.2016.08.521

7. Bailey PL, Rhondeau S, Schafer PG, Lu JK, Timmins $B S$, Foster W, et al. Dose-response pharmacology of intrathecal morphine in human volunteers. Anesthesiology. 1993;79(1):49-59. [PubMed] DOI: 10.1097/00000542-199307000-00010

8. Ganapathy S, Wasserman RA, Watson JT, Bennett J, Armstrong KP, Stockall CA, et al. Modified continuous femoral three-in-one block for postoperative pain after total knee arthroplasty. Anesth Analg. 1999;89:11971202. [PubMed]

9. Singelyn FJ, Deyaert $M$, Joris $D$, Pendeville $E$, Gouverneur JM. Effects of intravenous patientcontrolled analgesia with morphine, continuous epidural analgesia, and continuous three-in-one block on postoperative pain and knee rehabilitation after unilateral total knee arthroplasty. Anesth Analg. 1998 Jul;87(1):88-92. [PubMed] DOI: 10.1097/00000539199807000-00019

10. Allen HW, Liu SS, Ware PD, Nairn CS, Owens BD. Peripheral nerve blocks improve analgesia after total knee replacement surgery. Anesth Analg. 1998;87:9397. [PubMed] DOI: 10.1097/00000539-199807000$\underline{00020}$ 
11. Cheah JW, Sing DC, Hansen EN, Aleshi P, Vail TP. Does intrathecal morphine in spinal anesthesia have a role in modern multimodal analgesia for primary total joint arthroplasty? J Arthroplasty. 2018 Jun;33(6):16931698. [PubMed] DOI: $10.1016 /$. arth.2018.01.016

12. Suksompong $S$, Pongpayuha $P$, Lertpaitoonpan $W$, von Bormann B, Phanchaipetch T, Sanansilp V. Low-dose spinal morphine for post-thoracotomy pain: a prospective randomized study. J Cardiothorac Vasc Anesth. 2013;27:417-422. [PubMed] DOI: 10.1053/j.jvca.2012.12.003

13. Alsaeid MA, Sayed AM. Comparison between position change after low-dose spinal anesthesia and higher dose with sitting position in elderly patients: block characteristics, hemodynamic changes, and complication. Anesth Essays Res. 2019 JulSep;13(3):476-480. [PubMed] DOI: 10.4103/aer.AER_101_19
14. Chinachoti T1, Nilrat $P$, Samarnpiboonphol P. Nausea, vomiting and pruritus induced by intrathecal morphine. J Med Assoc Thai. 2013;96(5):589-594. [PubMed]

15. Kalso E. Effects of intrathecal morphine, injected with bupivacaine, on pain after orthopaedic surgery. $\mathrm{Br} \mathrm{J}$ Anaesth. 1983;55(5):415-422. [PubMed] DOI: $\underline{10.1093 / \mathrm{bja} / 55.5 .415}$

16. Kirson LE, Goldman JM, Slover RB. Low-dose intrathecal morphine for postoperative pain control in patients undergoing transurethral resection of the prostate. Anesthesiology. 1989;71(2):192-195. [PubMed] DOI: $10.1097 / 00000542-198908000-00004$

17. Ilfeld BM. Continuous peripheral nerve blocks: a review of the published evidence. Anesth Analg. 2011;113:904-925. [PubMed] DOI: 10.1213/ANE.0b013e3182285e01 